\title{
Mechanistic Studies of Continuous Glucose Upgrading Over Lewis Acidic Silicates by Operando UV-Vis and HSQC NMR
}

Botti, Luca; Meier, Sebastian; Hammond, Ceri

Published in:

A C S Catalysis

Link to article, DOI:

10.1021/acscatal.0c03638

Publication date:

2021

Document Version

Peer reviewed version

Link back to DTU Orbit

Citation (APA):

Botti, L., Meier, S., \& Hammond, C. (2021). Mechanistic Studies of Continuous Glucose Upgrading Over Lewis Acidic Silicates by Operando UV-Vis and HSQC NMR. A C S Catalysis, 11(3), 1296-1308.

https://doi.org/10.1021/acscatal.0c03638

\section{General rights}

Copyright and moral rights for the publications made accessible in the public portal are retained by the authors and/or other copyright owners and it is a condition of accessing publications that users recognise and abide by the legal requirements associated with these rights.

- Users may download and print one copy of any publication from the public portal for the purpose of private study or research.

- You may not further distribute the material or use it for any profit-making activity or commercial gain

- You may freely distribute the URL identifying the publication in the public portal 
This document is confidential and is proprietary to the American Chemical Society and its authors. Do not copy or disclose without written permission. If you have received this item in error, notify the sender and delete all copies.

\section{Mechanistic Studies of Continuous Glucose Upgrading Over Lewis Acidic Silicates by Operando UV-Vis and HSQC NMR}

\begin{tabular}{|c|c|}
\hline Journal: & ACS Catalysis \\
\hline Manuscript ID & CS-2020-036382.R2 \\
\hline Manuscript Type: & Article \\
\hline $\begin{array}{r}\text { Date Submitted by the } \\
\text { Author: }\end{array}$ & 12-Dec-2020 \\
\hline Complete List of Authors: & $\begin{array}{l}\text { Botti, Luca; Imperial College London, Department of Chemical } \\
\text { Engineering } \\
\text { Meier, Sebastian; Technical University of Denmark, Department of } \\
\text { Chemistry } \\
\text { Hammond, Ceri; Imperial College London, Department of Chemical } \\
\text { Engineering }\end{array}$ \\
\hline
\end{tabular}

\section{SCHOLARONE ${ }^{m}$ Manuscripts}




\begin{abstract}
Lewis acidic silicates are effective catalysts for the conversion of glucose to bio-molecules of industrial interest, such as methyl lactate and methyl vinyl glycolate. Although well studied in recent years, open questions of these processes remain, particularly in regards to elements of the reaction mechanisms, and how the catalysts deactivate during continuous operation. Such questions endure due to the lack of spectroscopic techniques capable of providing insight into the catalytic reaction at operational conditions. In this study, we follow the catalytic conversion of glucose over the Lewis acidic silicates Sn-Beta and Hf-Beta in a continuous flow reactor equipped with operando UVVis spectroscopy. In doing so, we identify several transient absorption features related to the activation and conversion of glucose at various operational conditions $\left(<170{ }^{\circ} \mathrm{C},<25 \mathrm{bar}\right)$. Additional spectroscopic studies (high-field ${ }^{1} \mathrm{H}-{ }^{13} \mathrm{C}$ HSQC NMR) and kinetic cross-experiments allow each Snglucose interaction to be assigned to a particular class of product, and hence to various selective or non-selective reaction pathways. Based on these assignments, operando UV-Vis is used to probe how partial deactivation of the stannosilicate catalyst affects the overall performance of the glucose upgrading reaction during continuous operation. We demonstrate how deactivation during glucose conversion is non-uniform, with different reaction pathways losing activity at different rates. These findings are shown to have consequences with respect to improving the selectivity of catalysts for glucose upgrading during continuous operation.
\end{abstract}




\section{Introduction}

Climate change coupled with population increase lends urgency to the development of environmentally sustainable processes for material and energy production. ${ }^{1-3}$ In this regard, the exchange of fossil feedstock with renewable sources of energy and carbon is a major target. Biomass shows potential as a sustainable feedstock for the production of important platform molecules, particularly when it can be converted to useful products by scalable chemo-catalytic methods. ${ }^{4,5}$ Of particular importance is the catalytic conversion of glucose, since glucose is the primary product of $\mathrm{CO}_{2}$ fixation and is the most common sugar gathered from agricultural waste biomass. ${ }^{6,7}$

One of the most promising catalysts for catalytic glucose conversion is Sn-Beta. ${ }^{8-12}$ Sn-Beta is a microporous zeolite in which tin atoms are isomorphously substituted into the otherwise siliceous Beta zeolite structure, where they behave as Lewis acid centres capable of activating and converting glucose ${ }^{8-12}$ A previous study by Tolborg et al. ${ }^{13}$ demonstrated that Sn-Beta can produce a variety of different terminal products starting from glucose, including: trans-2,5,6-trihydroxy-3-hexenoic methyl ester (THM) and furanics such as 5-(hydroxymethyl)furfural (HMF), all of which are derived from $\beta$ dehydration of 3-deoxyglucosone (3-DG) ( $\beta$-dehydration products); methyl lactate (ML) and methyl vinyl glycolate (MVG), derived from retro-aldol cleavage of hexoses (RA products); fructose and mannose, as products of glucose isomerization (GI products); methyl-glycosides, by alkylation of the monosaccharides in solution (alkylation products); and finally 3-deoxy- $\gamma$-lactones (3DGL), formed upon ring closure of 3DG (Scheme 1). ${ }^{13}$ Whilst the ability of Sn-Beta to catalyse so many reactions makes it a very interesting catalyst, it also makes control of the selectivity of the catalyst towards a specific chemical pathway very challenging. This is especially problematic in the context of process design, process economics and sustainable carbon management. 


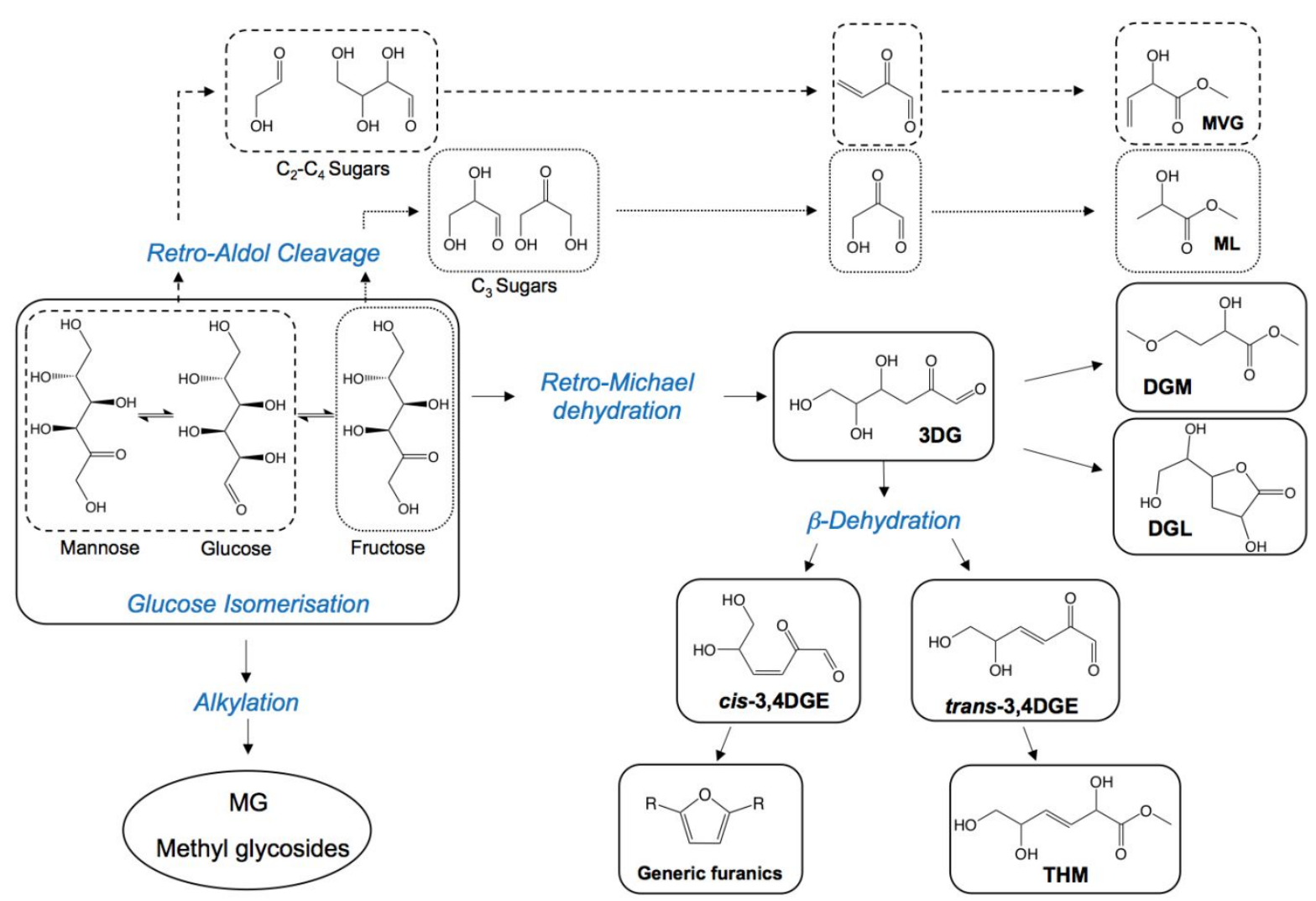

Scheme 1. Schematic representation of the reactions catalysed by Sn-Beta during glucose upgrading.

Although experimental works have shown that the catalyst composition, preparation methodology and reaction conditions (temperature, presence of alkali and/or water) can impact the final product distribution attained when converting glucose over Sn-Beta, ${ }^{13-16}$ few studies have addressed how the substrate (in this case glucose) interacts with the catalyst at operative conditions, ${ }^{13,17}$ or how to monitor the competition amongst these chemical pathways in the reaction environment.

A major obstacle towards addressing these open questions is the lack of spectroscopic insight into the operating catalytic reaction. In particular, the conditions at which glucose upgrading is carried out (liquid phase, $80-170^{\circ} \mathrm{C},<25$ bar when operating continuously ${ }^{15}$ ) makes in situ study of this system challenging. Consequently, existing spectroscopic and mechanistic studies of this system have relied on the correlation of kinetic data to various ex situ methodologies (e.g. MAS NMR), ${ }^{18-20}$ and/or to probe molecule studies that monitor the interaction of Sn-Beta with model compounds such as $\mathrm{CD}_{3} \mathrm{CN}$ and pyridine. ${ }^{21-25}$ An additional source of difficulty is that several of the compounds generated by SnBeta during these processes (Scheme 1) are not amenable to detection by routine chromatographic 
analyses, meaning that low carbon balances are usually reported. Together, these hurdles have made it difficult to understand the types of interaction that can occur between Sn and glucose, and how these interactions result in competing reaction pathways. ${ }^{26}$

In this manuscript, we follow the upgrading of glucose over several Sn- and Hf-silicate catalysts by operando UV-Vis spectroscopy. ${ }^{27}$ This technique is performed at operational conditions (in operando, $<150{ }^{\circ} \mathrm{C},<25$ bar) and is carried out in continuous flow, which allows simultaneous study of the deactivation of these interactions as a function of time on stream. To benchmark the UV-Vis absorptions detected in the operando reactor, high-field liquid-state NMR measurements $\left({ }^{1} \mathrm{H}-{ }^{13} \mathrm{C}\right.$ HSQC) are used to cross-correlate the optical intermediates to various products in solution, permitting each feature to be assigned to a particular class of reaction product and hence reaction pathway. ${ }^{26,28}$ Based on these findings, we later monitor the deactivation of stannosilicate catalysts for glucose conversion, allowing the deactivation of different reaction pathways to be monitored selectively during continuous operation.

\section{Results and Discussion}

\section{Identification of optical intermediates by operando UV-Vis spectra}

As described above, Sn-Beta is known to catalyse several selective and non-selective reaction pathways starting from glucose (Scheme 1). ${ }^{13}$ Although various reaction stimuli - including choice of catalyst, method of preparation and presence of additives in the reaction solution (particularly alkali and water $)^{14-16}$ - affect the course of the glucose conversion reaction over Sn-Beta, a dominating factor with respect to progress of the reaction is the choice of operational temperature. ${ }^{13,15}$ In particular, it has been established that GI is the dominant selective reaction pathway at temperatures of up to $110^{\circ} \mathrm{C}$, whereas RA processes become dominant as the temperature is increased beyond $110{ }^{\circ} \mathrm{C} .{ }^{13,15}$

Accordingly, preliminary operando UV-Vis studies were focused upon monitoring the conversion of glucose over Sn-Beta at various temperatures between 80 and $140{ }^{\circ} \mathrm{C}$ (see Supporting Information Figures S1-S3 for further details on the reactor). Each operando experiment was performed with a 
feed solution of 1 wt. \% glucose in methanol, and identical flow rates $\left(0.75 \mathrm{~mL} \mathrm{~min}^{-1}\right)$ and masses of catalyst $(0.1 \mathrm{~g}$ catalyst $)$ were employed in each experiment. Each individual experiment was performed with a fresh sample of catalyst, which in the case of these preliminary experiments was a sample of Sn-Beta containing 10 wt. \% Sn, and which was prepared by Solid State Incorporation (henceforth $10 \mathrm{Sn}$-Beta $\left.{ }_{\mathrm{SSI}}\right){ }^{29}$ Spectra were recorded after $0.5 \mathrm{~h}$ of time on stream to minimise the impact of catalyst deactivation, and all spectra were background corrected to the spectrum of the catalyst in a flow of pure methanol, i.e. to the state of the catalyst prior to introduction of glucose. The operando UV-Vis spectra generated by these reactions are illustrated in Figure 1. Due to the lack of extinction coefficient values for these intermediates, relative comparisons of intensity as a function of reaction perturbation were used for comparative purposes.
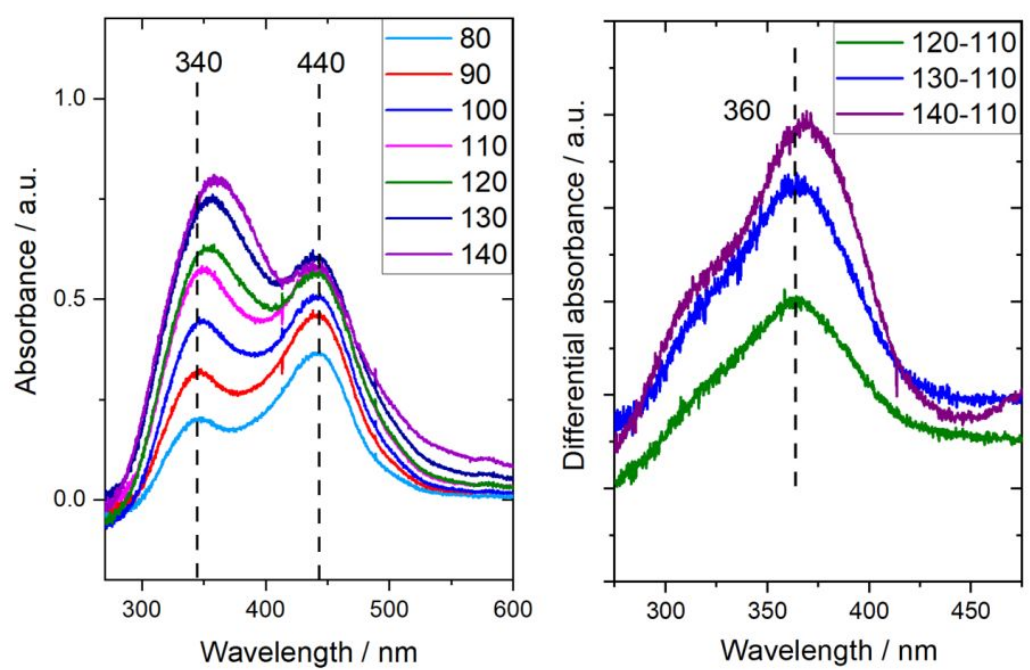

Figure 1. (Left) Operando UV-Vis for glucose conversion over $10 \mathrm{Sn}-\mathrm{Beta}_{\mathrm{ssI}}$ between $80-140{ }^{\circ} \mathrm{C}$. (Right) Differential operando UV-Vis spectrum in the 250-450 region, achieved by subtracting the spectrum of the experiment at $110{ }^{\circ} \mathrm{C}$ from those generated between $120-140{ }^{\circ} \mathrm{C}$. Reaction conditions: 1 wt. \% glucose in methanol, $0.75 \mathrm{~mL} \mathrm{~min}^{-1}, 0.1 \mathrm{~g}$ catalyst, various reaction temperatures between $80-140{ }^{\circ} \mathrm{C}$.

As can be seen in Figure 1, several absorption intermediates were generated during the interaction of glucose and 10Sn-Beta ${ }_{\mathrm{SSI}}$. At the lowest temperature studied $\left(80^{\circ} \mathrm{C}\right)$, spectra consisted of two major absorptions, centred at $\lambda=340 \mathrm{~nm}$ and $440 \mathrm{~nm}$ (henceforth, $\lambda_{340}$ and $\lambda_{440}$ ). However, the behaviour of these features as a function of temperature differed substantially. The $\lambda_{440}$ absorption was the most intense feature observed at $80{ }^{\circ} \mathrm{C}$, but increased only marginally upon increasing the temperature from 80 to $110{ }^{\circ} \mathrm{C}$, after which the intensity of the feature plateaued further. In contrast, the $\lambda_{340}$ absorption 
was present at a much lower intensity at $80^{\circ} \mathrm{C}$, but increased steeply at higher temperatures, reaching its maximum intensity at $140{ }^{\circ} \mathrm{C}$ (Figure 1 , left). Alongside these changes was an evident shift in the position of the $\lambda_{340}$ feature upon increasing the temperature beyond $110^{\circ} \mathrm{C}$. Analysis of the differential spectra generated by subtraction of the $110{ }^{\circ} \mathrm{C}$ spectrum from those generated at higher temperature (Figure 1, right) revealed that this shift was caused by the generation of a new contribution at $\lambda_{360}$.

Control experiments confirmed that the absorptions described in the previous section were only generated when glucose and Sn were both present in the system. ${ }^{15}$ Specifically, these absorptions were not formed when methanol was flowed over Sn-Beta, or when the reaction solution ( 1 wt. \% glucose in methanol) was flowed over Sn-free zeolite Beta (Figure S4), meaning that the co-presence of Sn and substrate is paramount for these absorptions to arise. ${ }^{15}$ To verify that these absorptions did not simply arise through formation of a chromophoric (by-)product of the reaction, the reaction effluent and standards of glucose and High Fructose Corn Syrup (HFCS, $42 \%$ glucose) were also monitored by ex situ UV-Vis (SI Figure S5). Interestingly, whilst the reaction effluent showed a broad absorption at high energy $(250-300 \mathrm{~nm})$ - confirming the presence of some chromophoric by-product in the reaction solution - none of these solutions exhibited absorptions at $340 \mathrm{~nm}$ and $440 \mathrm{~nm}$. As the $\lambda_{340}$ and $\lambda_{440}$ bands were only formed in the presence of glucose and $\mathrm{Sn}$, but did not relate to individual compounds formed during reaction, they can be assigned to absorbing species present due to the interaction between $\mathrm{Sn}$ and glucose. To further verify this, additional ex situ UV-Vis analyses were performed on Sn-Beta samples removed from the reactor following glucose upgrading in methanol (SI Figure S6). These measurements revealed that the absorption features described above were still visible on the catalyst even after its removal from the reaction environment, verifying that they are related to catalyst-substrate interactions (SI Figure S6).

To determine the relevance of the findings from Figure 1, the reaction effluent of each experiment was analysed by classic chromatographic techniques (HPLC-ELSD/UV and GC-FID, Figure 2). Although all of the products detected by chromatographic techniques were generated by the Lewis acid active sites of the catalyst (no products were observed when Sn-free zeolite Beta was used as catalyst), and hence are examples of selective reaction products, they can be further categorised as GI products (fructose, mannose) and RA products (ML and MVG). ${ }^{13}$ 
Figure 2. Yields of fructose, mannose (GI products), methyl lactate and methyl vinyl glycolate (RA products) achieved during the conversion of glucose by $10 \mathrm{Sn}-\mathrm{Beta}_{\mathrm{SSI}}$ at various temperatures. Reaction conditions: 1 wt. \% glucose in methanol, $0.75 \mathrm{~mL} \mathrm{~min}{ }^{-1}, 0.1 \mathrm{~g}$ catalyst, various reaction temperatures between $80-140{ }^{\circ} \mathrm{C}$.

At lower temperatures $\left(80-110^{\circ} \mathrm{C}\right)$, GI products were the dominant products in the reaction effluent, the yields of which increased from $7 \%$ at $80{ }^{\circ} \mathrm{C}$, to $26 \%$ at $110{ }^{\circ} \mathrm{C}$ (Figure 2 ). However, even at these low temperatures, a substantial decrease in carbon balance was observed. This loss of carbon balance suggests that by-products not amenable to chromatographic analysis were already present in the effluent even at low temperature. Notably, the carbon balance in each of the low temperature reactions was comparable (ca. $75 \%$ ), indicating that the by-products formed at low temperature were not strongly impacted by the choice of temperature in this range.

Interestingly, although raising the temperature above $110^{\circ} \mathrm{C}$ resulted in a substantial increase in the quantity of substrate converted - which increased from $55 \%$ at $110{ }^{\circ} \mathrm{C}$ to $>90 \%$ at $140{ }^{\circ} \mathrm{C}-$ the overall yield of selective products (GI+RA) increased only slightly from $26 \%$ to $30 \%$. Accordingly, a second major loss of carbon balance was observed in the higher temperature regime $\left(>110^{\circ} \mathrm{C}\right)$, the onset of which coincided with the generation of $\lambda_{360}$ feature (Figure 1, right). Alongside this loss of carbon balance, the distribution of selective products also changed in the higher temperature regime, and RA products accounted for an increasing fraction of the selective products in the effluent. Figure 2 thus confirms that the cumulative yield of the products, the distribution of products between GI and 
RA, the overall carbon balance (and hence, quantity of by-products), and the intensity of the operando UV-Vis absorbances, all strongly depend upon the reaction temperature.

To gain further insight, the evolution of the operando UV-Vis spectra as a function of time on stream was investigated. In particular, operando spectra of the glucose conversion reaction at $110{ }^{\circ} \mathrm{C}$ were recorded at several stages of a $13 \mathrm{~h}$ continuous reaction period. This temperature was chosen as it provided a balance between the maximal yield of desired products (GI+RA), the carbon balance of the process, and the presence of all absorption features.
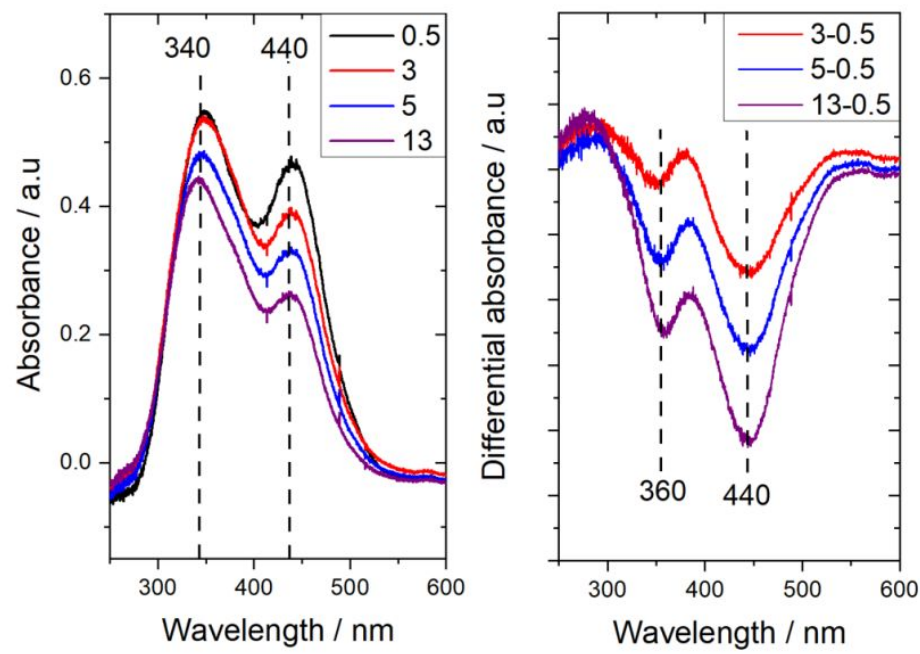

Figure 3. (Left) Operando UV-Vis spectra from the glucose conversion reaction catalysed by $10 \mathrm{Sn}-\mathrm{Beta}_{\mathrm{SSI}}$ at $110{ }^{\circ} \mathrm{C}$, recorded at various points of time on stream $(0.5,3,5$ and $10 \mathrm{~h}$ ). (Right) Differential operando UV-Vis spectra in the $250-600 \mathrm{~nm}$ region, obtained by subtracting the spectrum recorded at $0.5 \mathrm{~h}$ on stream from those at later points of time. Reaction conditions: $1 \mathrm{wt} . \%$ glucose in methanol, $0.75 \mathrm{~mL} \mathrm{~min}{ }^{-1}, 0.1 \mathrm{~g}$ catalyst, $110{ }^{\circ} \mathrm{C}$.

As can be seen (Figure 3, left), over the course of $13 \mathrm{~h}$ on stream, the absorptions present in the operando UV-Vis spectra decreased in intensity. However, the rate of decrease differed markedly for the different bands in the spectra, as the $\lambda_{440}$ signal lost intensity more rapidly than the $\lambda_{340}$ signal (SI Figure S7). Moreover, the $\lambda_{340}$ band also shifted towards higher energy, suggesting a non-uniform loss of intensity in the 330-380 $\mathrm{nm}$ region. To clarify the changes observed as a consequence of time on stream, differential spectra were generated by subtracting the spectrum recorded at $0.5 \mathrm{~h}$ on stream from those collected at later times (Figure 3, right). Consequently, signals that diminish in intensity over the relevant time period appear negative as a consequence of subtracting the spectrum at time 0.5 
hours from each spectrum at time " $t$ ". This analysis revealed that the $\lambda_{340}$ band was a congested feature of an absorbance at approximately $330 \mathrm{~nm}$ (henceforth $\lambda_{330}$ ), and a second absorbance at 360 $\mathrm{nm}\left(\lambda_{360}\right)$, which deactivated much faster over the first 10 hours of the reaction. This finding indicates that although the $\lambda_{360}$ feature observed in Figure 1 grows in strongly at higher temperatures, it was already present at $110^{\circ} \mathrm{C}$, accounting for the progressive shift of the maxima to higher wavelengths at increasing temperature. As a consequence of the loss of intensity at 360 and $440 \mathrm{~nm}$, the $\lambda_{330} \mathrm{UV}$-Vis band became the most dominant after $10 \mathrm{~h}$ on stream, with the majority of its intensity remaining after this operational period.

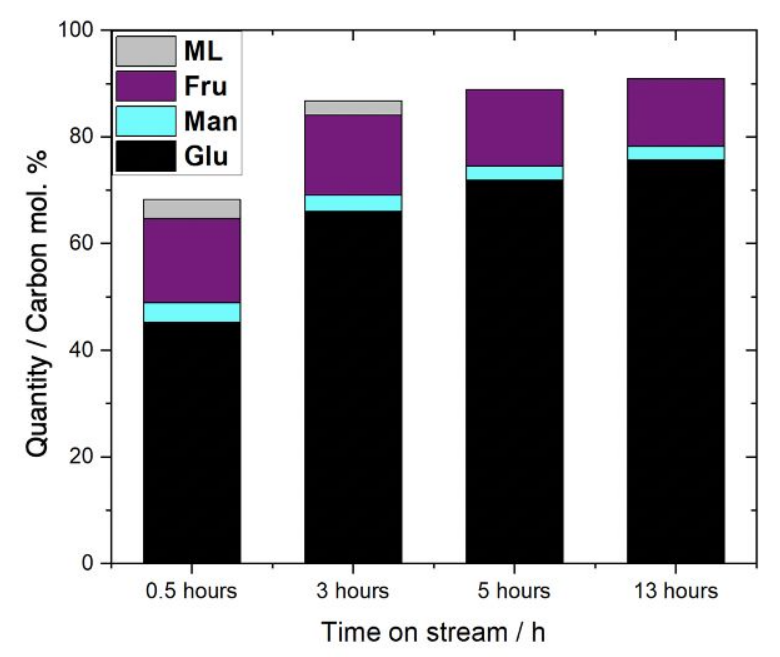

Figure 4. Kinetic data related to the conversion of glucose over $10 \mathrm{Sn}$-Betassi at $110{ }^{\circ} \mathrm{C}$ at various points of time on stream $\left(0.5,3,5\right.$ and $13 \mathrm{~h}$ ). Reaction conditions: $1 \mathrm{wt}$. \% glucose in methanol, $0.75 \mathrm{~mL} \mathrm{~min}^{-1}, 0.1 \mathrm{~g}$ catalyst, $110^{\circ} \mathrm{C}$.

Quantitative analysis of the reaction effluent revealed that the yield of selective products (GI+RA) decreased only slightly from $22 \%$ to $16 \%$ (Figure 4 ) over the $13 \mathrm{~h}$ reaction period. However, the quantity of glucose converted by the catalyst decreased much more dramatically, from $55 \%$ at $0.5 \mathrm{~h}$ to $22 \%$ at $13 \mathrm{~h}$ ). As a consequence, the carbon balance of the reaction increased substantially over the first $13 \mathrm{~h}$ on stream (from 65 to $90 \%$, Figure 4). The increased carbon balance during continuous operation indicates that undetected by-products were produced to a much lower level after $13 \mathrm{~h}$ on stream. As such, the decrease in absorbance appears to be primarily related to an increase in the selectivity of the catalyst over this period of operation. 
Given that several of the products obtained by conversion of glucose are not amenable to detection by classical chromatographic means (as evidenced by the low carbon balances in Figure 2 and Figure 4), further analysis of the post-reaction effluents was undertaken by high-field liquid NMR $\left({ }^{1} \mathrm{H}-{ }^{13} \mathrm{C}\right.$ HSQC NMR spectroscopy). ${ }^{26,28}$ This method provides roughly 30 times higher sensitivity compared to conventional $1 \mathrm{D}{ }^{13} \mathrm{C}$ NMR, whilst providing improved resolution due to its two-dimensional nature. As demonstrated in recent studies, ${ }^{26,28}$ the methodology can be used to describe several products from the Lewis acid catalysed conversion of glucose, and provides an unbiased representation of by-product formation since it is also sensitive to compounds that are not easily detected with classical chromatographic methods. ${ }^{26,28}$ The spectra of the two effluents measured by HSQC NMR $(0.5 \mathrm{~h}$ and $13 \mathrm{~h}$ on stream) are shown in Figure 5.

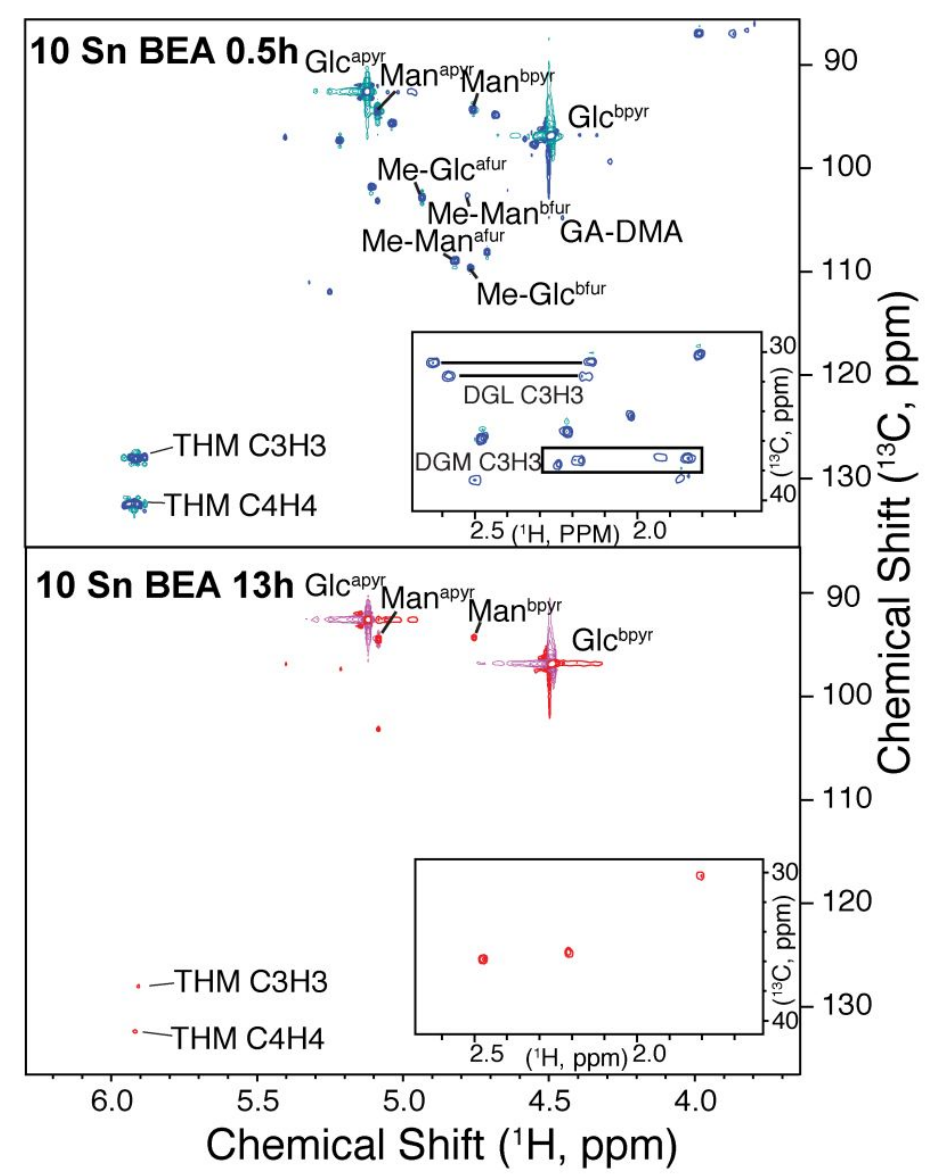

Figure 5. 2D ${ }^{1} \mathrm{H}-{ }^{13} \mathrm{C}$ HSQC NMR spectra of the effluent of the reactions reported in Figure 4 at 0.5 and $13 \mathrm{~h}$ on stream. $\mathrm{CH}$ groups are labelled by their position, except for $\mathrm{C} 1 \mathrm{H} 1$ (hemi)acetal groups in carbohydrates, glycosides and aldehyde-containing furanics. 
2D ${ }^{1} \mathrm{H}-{ }^{13} \mathrm{C}$ HSQC NMR spectra of the reaction effluent samples at $0.5 \mathrm{~h}$ and $13 \mathrm{~h}$ are displayed in Figure 5. This analysis demonstrated that the $0.5 \mathrm{~h}$ reaction effluent contained high quantities of THM, 3DGL, 3-deoxy-gluconic methyl ester (DGM) and furanics. According to recent studies by Tolborg et al., these molecules can all be produced from $\beta$-dehydration of the same intermediate compound (3DG), which is itself formed by retro-Michael dehydration of glucose. ${ }^{13}$ Large quantities of alkylation products (methyl-glucoside and methyl-mannoside) were also present at 0.5 hours of time on stream. Notably, the quantity of $\beta$-dehydration and alkylation products strongly decreased after 13 hours of time on stream, over the same period of time as the intensity at $\lambda_{440}$ and $\lambda_{360}$ decreased, and the carbon balance of the reaction increased from 65 to $90 \%$ (Figure 4). Based on these observations, it can tentatively be ascribed that absorptions at $\lambda_{360}$ and $\lambda_{440}$ relate to the generation of non-selective by-products, whilst the residual $\lambda_{330}$ absorption relates to selective reaction pathways (GI and/or RA),

\section{Assignment of selective reaction pathways}

To further verify these generalised assignments $\left(\lambda_{330}=\right.$ selective, and $\lambda_{360}$ and $\lambda_{440}=$ non-selective $)$, a variety of additional operando UV-Vis experiments were performed. Firstly, operando UV-Vis was performed on a sample of Hf-containing zeolite Beta, which we recently demonstrated to be able to selective catalyse GI to thermodynamic equilibrium without initiating non-selective pathways. ${ }^{30} \mathrm{We}$ note that the basic characterisation of this material was recently published in reference 30 .
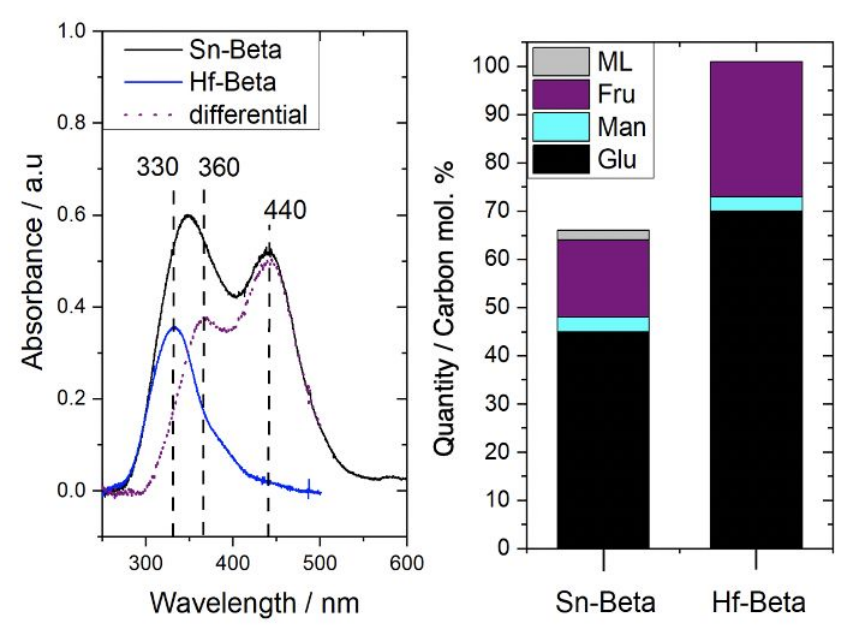
Figure 6. (Left) Operando UV-Vis spectra recorded during glucose conversion over Hf-Beta (blue line) and 10Sn-BetassI (black line) at $110{ }^{\circ} \mathrm{C}$. The dotted line is the differential spectrum achieved by subtraction of the Hf-Beta spectrum from the spectrum of $10 \mathrm{Sn}$-BetassI. (Right) Distribution of reactant and product species in the effluent of both reactions as monitored by chromatographic methods. Reaction conditions: 1 wt. \% glucose in methanol, $0.75 \mathrm{~mL} \mathrm{~min}^{-1}(\mathrm{Sn})$ and $0.65 \mathrm{~mL} \mathrm{~min}^{-1}(\mathrm{Hf}), 0.1 \mathrm{~g}$ catalyst, $110{ }^{\circ} \mathrm{C}$.

Figure 6 shows the operando UV-Vis spectrum generated by the catalytic conversion of glucose over Hf-Beta at $110{ }^{\circ} \mathrm{C}(\mathrm{Si} / \mathrm{Hf}$ molar ratio of 200$)$, alongside the operando UV-Vis spectrum from the $10 \mathrm{Sn}-\mathrm{Beta}_{\mathrm{SSI}}$ catalysed reaction at otherwise identical conditions. Spectra recorded at $0.5 \mathrm{~h}$ on stream were used for evaluation in order to be consistent with the data presented in Figure 1. We also note that Hf-Beta was first activated in a flow of methanol for $20 \mathrm{~h}$ prior to reaction, which we recently demonstrated to be important for activity to be observed during low temperature GI. ${ }^{30}$ Whilst the operando UV-Vis spectra generated during glucose upgrading at $110^{\circ} \mathrm{C}$ with $\mathrm{Sn}$-Beta consisted of absorbances at $\lambda_{440}, \lambda_{330}$ and $\lambda_{360}$, the spectra from Hf-Beta did not show any absorbance at $\lambda_{440}$ (Figure 6, left). Moreover, although the overall intensity of the spectrum was lower in the 330-380 nm region, this was clearly due to the absence of any major absorbance at $\lambda_{360}$, as highlighted by the differential spectrum.

Kinetic data generated during these experiments are shown in Figure 6, right. In line with our recent studies, the reaction effluent generated during the continuous conversion of glucose over Hf-Beta ${ }^{30}$ only contained detectable quantities of glucose, fructose and mannose, with no loss of carbon balance observed. At the reaction conditions measured, the total yield of selective (GI) products when using Hf-Beta was $30 \%$. In contrast, at the same conditions using 10 Sn-Beta 5 sI as catalyst, the level of conversion was much higher ( $55 \%$ versus $30 \%$ ), but the total yield of selective products was only 24 $\%$, confirming the poorer selectivity performance of Sn-Beta. Consequently, the carbon balance of the Sn-Beta reaction was much lower, with approximately $35 \%$ of the initial carbon being converted into by-products not amenable to chromatographic detection. The presence of a single absorbance at $\lambda_{330}$ for the catalyst exhibiting quantitative selectivity to GI and no loss in carbon balance supports assignment of the $\lambda_{330}$ absorption to selective glucose conversion, and the $\lambda_{360}$ and $\lambda_{440}$ bands to nonselective reaction pathways. 
In addition to GI, RA processes also represent a selective glucose conversion pathway. Recently, it has been reported that a key product in the RA pathway is 3DG, which is formed by retro-Michael dehydration of glucose (Scheme 1). However, in addition to being a key intermediate for RA product formation, 3DG is also a key intermediate in the non-selective $\beta$-dehydration pathway. ${ }^{12,13,31}$ Thus, in order to aid the assignment of a signal for RA product formation, the conversion of dihydroxyacetone (DHA) to ML was studied. During this reaction, retro-Michael dehydration of DHA to pyruvaldehyde (PVA) must occur in order for ML to be produced (Scheme 2). ${ }^{12,32}$ The reaction leading to PVA occurs via a pathway that is analogous to the formation of 3DG from glucose, and reportedly employs similar catalyst-substrate coordination. ${ }^{12,13,33}$ However, this reaction cannot lead to any further $\beta$-dehydration due to the absence of a hydroxylated $\mathrm{C}_{4}$ atom.

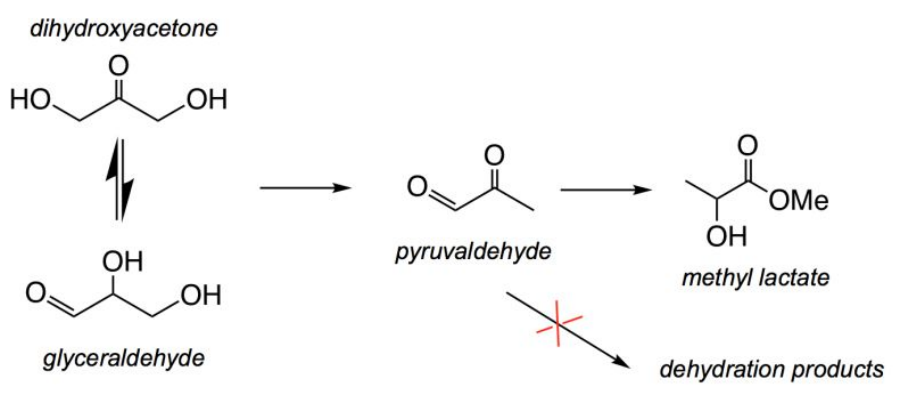

Scheme 2. Scheme of the processes related to the conversion of dihydroxyacetone to methyl lactate.
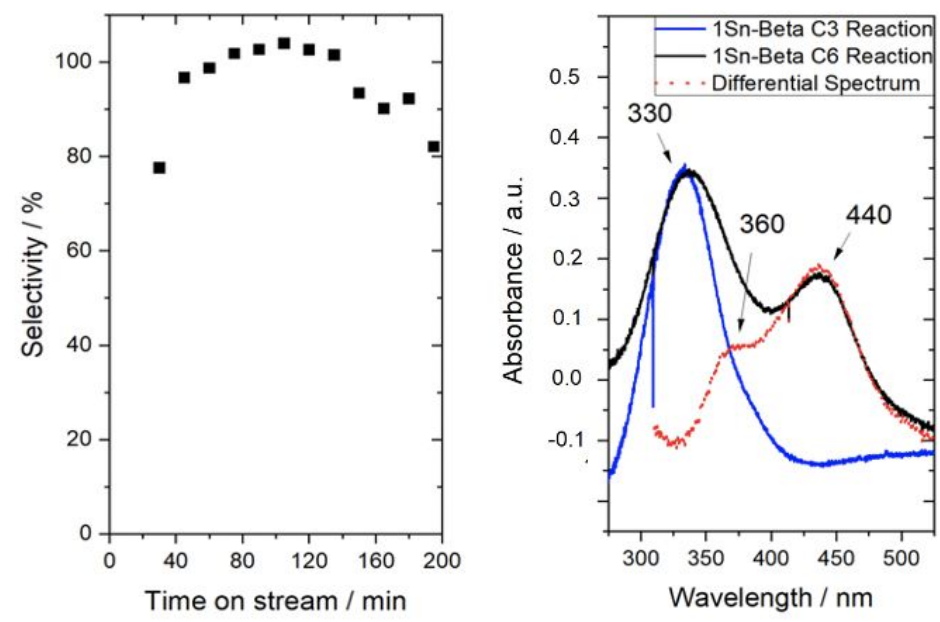

Figure 7. (Left) ML selectivity during the conversion of DHA to ML as a function of time on stream over 1SnBetassi at $110^{\circ} \mathrm{C}$. (Right) Operando UV-Vis spectra generated during the conversion of DHA to ML over 1SnBeta $_{\text {ssI }}$ at $110^{\circ} \mathrm{C}$, compared to the spectrum generated from the analogous reaction starting from glucose. Reaction conditions: $1 \mathrm{wt}$ \% glucose in methanol, $0.75 \mathrm{~mL} \mathrm{~min}^{-1}, 0.1 \mathrm{~g}$ catalyst, $110^{\circ} \mathrm{C}$. 
The conversion of DHA to ML was performed at $110^{\circ} \mathrm{C}$ with $1 \%$ wt. Sn loaded Sn-Beta (henceforth 1 Sn-Beta ${ }_{\text {SSI }}$ ) as the catalyst. This catalyst was chosen since most previous works in the literature for this reaction use low loaded samples of Sn-Beta $\left(<2 \%\right.$ wt. Sn). ${ }^{32,34}$ The absence of $\beta$-dehydration pathways resulted in ML being formed at a selectivity close to $100 \%$ throughout the reaction period (Figure 7). Spectra generated by operando UV-Vis analysis of this reaction clearly demonstrated that the reaction was accompanied by a single absorption centred at $\lambda_{330}$, with minimal absorption evident at $\lambda_{360}$ and $\lambda_{440}$. To further probe these signals, the spectrum generated at $0.5 \mathrm{~h}$ time on stream during the conversion of DHA to ML over 1 Sn-Beta ${ }_{\text {SSI }}$ was compared to the spectrum generated during the glucose conversion reaction at otherwise identical conditions. The red dots in Figure 7 show the difference between these two spectra, achieved by subtracting the DHA spectrum from that achieved from the glucose upgrading reaction. The differential spectrum clearly shows that the $\mathrm{C}_{3}$ reaction primarily exhibited an intense absorption at $\lambda_{330}$, whereas the $\mathrm{C}_{6}$ reaction exhibited a dominant signal at $\lambda_{330}$, but also significant absorptions at $\lambda_{360}$ and $\lambda_{430}$. These findings support the hypothesis that the RA reaction intermediates are also embedded beneath $\lambda_{330}$, along with the intermediates related to GI. More broadly, this analysis is indicative that the $\lambda_{330}$ band relates to the coordination of $\mathrm{Sn}$ with the carbonyl and hydroxyl groups of the substrate molecule (vide infra). It is noted that whilst the spectrum of the DHA reaction still shows a slight shoulder at $360 \mathrm{~nm}$, this most likely arises from the formation of traces of hexoses due to aldol condensation of two molecules of $\mathrm{C}_{3}$, which can then be transformed by the classic glycolytic pathways shown in Scheme $1 .{ }^{13}$

To further aid the assignment of the optical features related to 3DG and the selective RA pathway, the effect of alkali on the reaction system was also investigated. It is widely reported in the literature that adding alkali salts to the reaction feed dramatically increases the selectivity of the glucose conversion reaction towards RA products. ${ }^{13,14}$ Accordingly, the impact of alkali addition was evaluated for $1 \mathrm{Sn}$ Beta $_{\text {SSI }}$ by recording the operando spectra of this catalyst in the absence and in the presence of alkali in the reaction feed. $\mathrm{KCl}\left(4 \mathrm{mg} \mathrm{L}^{-1}\right)$ was chosen as alkali additive because its wide range of effective concentration permits easier utilisation in continuous flow, and its limited basicity does not strongly impact glycoside formation in the same way as achieved by $\mathrm{K}_{2} \mathrm{CO}_{3}$, which could indirectly aid 
assignment of the non-selective bands. ${ }^{28}$ The reaction was performed at high temperature $\left(150{ }^{\circ} \mathrm{C}\right)$, since the effect of alkali is more pronounced during the formation of RA products formed during the high temperature selective pathway. ${ }^{28}$ A low loaded sample of Sn-Beta $(1$ wt. \%) was again used for this experiment since the effect of alkali has only been confirmed for such materials..$^{15,32}$

Figure 8 presents the operando UV-Vis spectra following the effect of alkali $(\mathrm{KCl})$ during glucose conversion over $1 \mathrm{Sn}$-Beta ${ }_{\mathrm{SSI}}$, alongside the kinetic data obtained in the presence and in the absence of alkali. Interestingly, in the presence of alkali, the system showed a much sharper $\lambda_{330}$ absorption, a notable decrease in intensity for $\lambda_{360}$, and a very minor decrease in intensity for $\lambda_{440}$. The differential spectrum (red) of the two stages of reaction clarifies how the presence of alkali salts impacted the optical properties of the system, particularly the intensity of $\lambda_{360}$, which was minimised substantially. We note that the limited change in absorbance at $440 \mathrm{~nm}$ could be an early indication that this particular non-selective absorbance arises from glycoside formation, since the limited basicity of $\mathrm{KCl}$ has been shown to leave the alkylation pathway largely unaffected. ${ }^{28}$
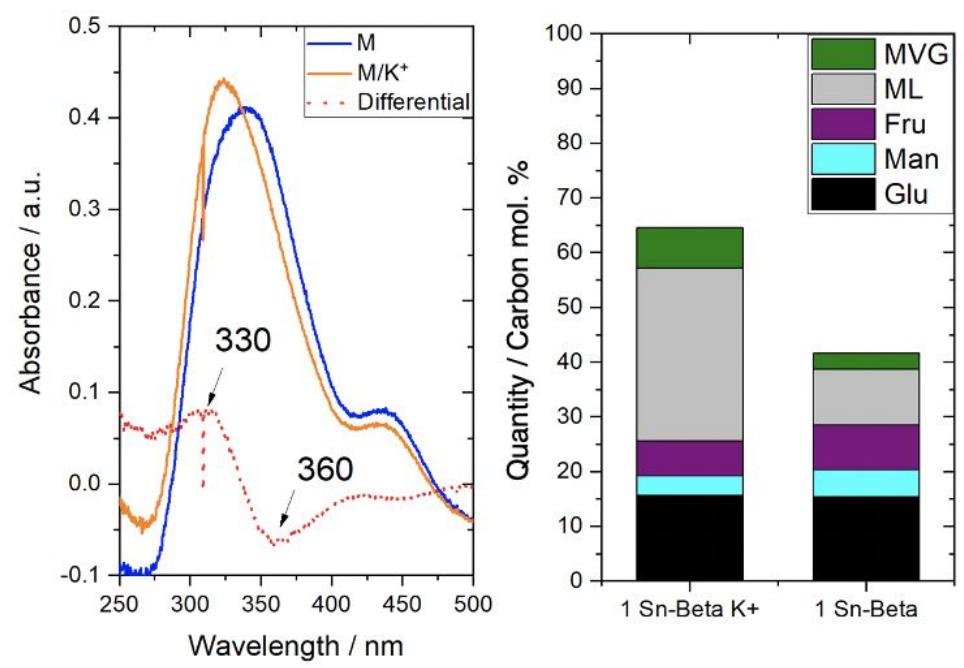

Figure 8. (Left) Operando UV-Vis spectra generated during the conversion of glucose by $1 \mathrm{Sn}-\mathrm{Beta}$ SsI in the presence (orange line) and in the absence (blue line) of $\mathrm{KCl}$ at $150{ }^{\circ} \mathrm{C}$ (blue line). The dotted red spectrum shows the difference of these two spectra. (Right) Distribution of reactant and product species in the effluent of the reaction in the absence and presence of alkali. Reaction conditions: $1 \mathrm{wt}$ \% glucose in methanol containing $\mathrm{KCl}$ (4 mg L-1), $0.75 \mathrm{~mL} \mathrm{~min}^{-1}, 0.1 \mathrm{~g}$ catalyst, $150^{\circ} \mathrm{C}$. 
When evaluating the impact of alkali on the kinetic performance of Sn-Beta (Figure 8, right), the most evident impact was the substantial increase of ML yield from 12 to $40 \%$ upon inclusion of alkali. As yields to GI products and the quantity of glucose converted were largely unchanged, the carbon balance increased dramatically upon addition of alkali, suggesting that the addition of alkali led to lower quantities of by-products. The increase in the yield of RA products and increase in carbon balance was accompanied by an increase in absorbance at $\lambda_{330}$ and a decrease in absorbance at $\lambda_{360}$. These findings further indicate that the optical features associated with RA formation are embedded within the $\lambda_{330}$ region, and that the $360 \mathrm{~nm}$ region is associated with non-selective by-products.

From the data presented in this section, it is apparent that both the RA pathway (via 3DG) and the GI pathway are characterised by an absorbance at $\lambda_{330}$. Although each pathway would likely require the coordination of different carbonyl and hydroxyl groups, this observation can be taken as evidence that both selective pathways proceed via similar catalyst-substrate intermediates, which has previously been proposed in the literature but has not been supported experimentally to date. ${ }^{12,13,35,36}$.

\section{Assignment of non-selective pathways $\left(\lambda_{440}\right.$ and $\left.\lambda_{360}\right)$}

Correlations of spectroscopic and reactivity data strongly indicate that the $\lambda_{330}$ feature relates to the selective conversion of glucose, either through isomerisation or retro-aldol fragmentation, whereas the $\lambda_{360}$ and $\lambda_{440}$ features arise from non-selective reaction pathways. These non-selective pathways include products derived from $\beta$-dehydration and alkylation, as evidenced by chromatographic analysis and NMR spectroscopy. To better understand the nature of the $\lambda_{360}$ and $\lambda_{440}$ features, additional correlations were sought, with the aim of assigning both features to a specific non-selective reaction pathway.

As demonstrated in Figure 1, the two non-selective bands exhibited very different dependence on temperature. Specifically, whereas the $\lambda_{440}$ feature was clearly generated at low temperature but increased only marginally with increasing reaction temperature, the $\lambda_{360}$ feature was absent at low temperature but became dominant at higher temperature. Recently, Tolborg et al. ${ }^{13}$ reported a study 
focused upon the prevalence of by-products during the catalytic conversion of glucose over Sn-Beta between temperatures of $90-180^{\circ} \mathrm{C}$. During this investigation, the authors revealed that by-products in the low temperature regime mainly consisted of glycosidic compounds such as methyl glucopyranoside (Me-Glu) and methyl fructofuranoside (Me-Fru). Upon raising the reaction temperature beyond $110{ }^{\circ} \mathrm{C}$, contributions from glycosidic compounds decreased, and by-products from $\beta$-dehydration and furanic production came to dominate. Graphic representation of the published data (SI Figure S8) shows how the behaviour of these two classes of compounds differed markedly with temperature. Based on this behaviour and the temperature dependences of the $\lambda_{360}$ and $\lambda_{440}$ features, it can be hypothesised that the low temperature $\lambda_{440}$ feature arises from glycosidic pathways, whereas the high temperature absorbance at $\lambda_{360}$ arises from $\beta$-dehydration. Added support for this preliminary assignment can be gained from the observation that the addition of $\mathrm{KCl}$ (Figure 8) decreased the magnitude of the $\lambda_{360}$ feature to a much greater extent $\lambda_{440}$, which is of relevance since it has been reported that $\mathrm{KCl}$ does not overly impact the glycosidic reaction pathway unlike more basic alkali additives. ${ }^{28}$

To gain experimental support of this hypothesis, two catalysts samples were studied by operando UVVis. These included 1 Sn-Beta $s$ ( by classical hydrothermal synthesis ${ }^{37}$ (henceforth, 1 Sn-Beta $\mathrm{HDT}_{\text {). The }}$ basic characterisation of these samples (XRD, porosimetry, ${ }^{119}$ Sn MAS NMR) was recently reported in detail. ${ }^{17}$ To obtain maximum insight from these experiments, glucose conversion was performed at $130^{\circ} \mathrm{C}$, in order to further stimulate generation of the $\lambda_{360}$ feature, which only weakly contributed to the spectra at lower temperatures (Figure 9).

Figure 9 Left presents the operando UV-Vis spectra of glucose upgrading carried out at $130{ }^{\circ} \mathrm{C}$ by the two different samples of $1 \mathrm{Sn}$-Beta, alongside the kinetic data obtained from each experiment. As can be seen, the spectrum obtained with $1 \mathrm{Sn}-$ Beta $_{\mathrm{SSI}}$ was consistent with that obtained for $10 \mathrm{Sn}-\mathrm{Beta}_{\mathrm{SSI}}$ at the same temperature, demonstrating a strong absorbance in the $330-380 \mathrm{~nm}$ region, alongside a somewhat less intense absorbance at $\lambda_{440}$. In contrast, the spectrum of 1 Sn-Beta $a_{\mathrm{HDT}}$ exhibited negligible absorbance at $\lambda_{440}$, but exhibited much more intense absorbances in the 330-380 nm region. 
Along with increased absorbance in the $330-380 \mathrm{~nm}$ region, the maximum was also clearly shifted to $\lambda_{330}$ when 1 Sn-Beta ${ }_{\text {HDT }}$ was used as catalyst.
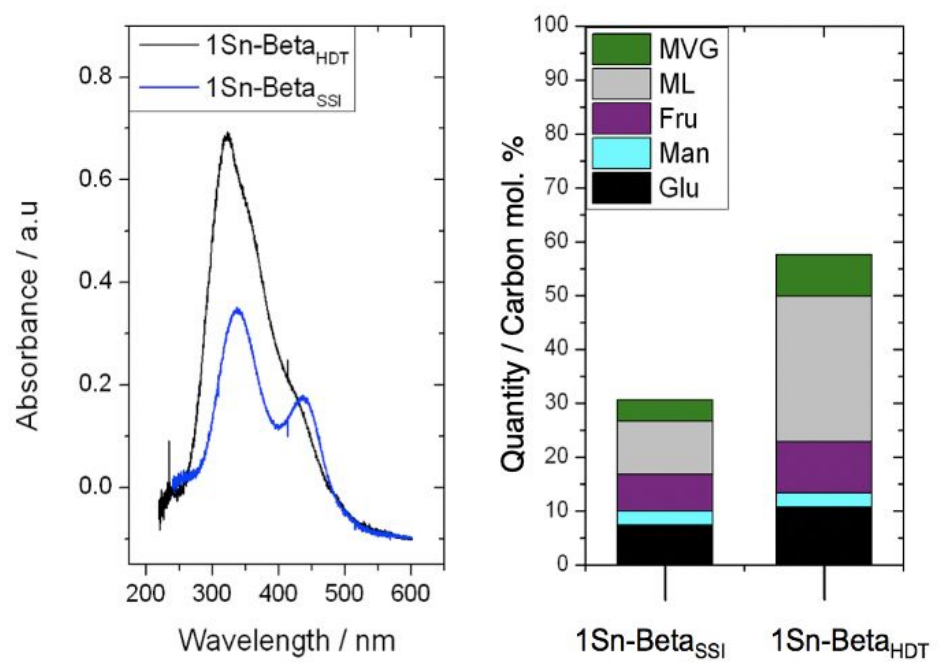

Figure 9. (Left) Operando spectra of the glucose upgrading reactions catalysed by 1 Sn-Beta $1 \mathrm{Sn}-\mathrm{Beta}_{\mathrm{HDT}}$ (black line) at $130{ }^{\circ} \mathrm{C}$, recorded at $0.5 \mathrm{~h}$ on stream. (Right) Distribution of reactant and product species in the effluent of the glucose conversion reaction catalysed by $1 \mathrm{Sn}-\mathrm{Beta}_{\mathrm{SSI}}$ and $1 \mathrm{Sn}-\mathrm{Beta}$ HDT. Reaction conditions: $1 \mathrm{wt}$. $\%$ glucose in methanol, $0.5 \mathrm{~mL} \mathrm{~min}^{-1}, 0.1 \mathrm{~g}$ catalyst, $130{ }^{\circ} \mathrm{C}$.

The product yields related to these two operando spectra are displayed in Figure 9, right. Whilst both experiments exhibited comparable levels of glucose conversion (ca. $90 \%$ ), much higher yields of selective products were obtained over $1 \mathrm{Sn}-\mathrm{Beta}_{\mathrm{HDT}}(45 \%)$ than over $1 \mathrm{Sn}-\mathrm{Beta}_{\mathrm{SSI}}(22 \%)$. This change in selectivity confirms the better performance of the hydrothermal material for conversion of glucose, in line with previous kinetic studies. In the context of this study, the higher yield of selective products obtained with $1 \mathrm{Sn}-\mathrm{Beta}_{\mathrm{HDT}}$ correlates with its increased absorbance at $\lambda_{330}$, and further supports assignment of the $\lambda_{330}$ feature to the selective reaction pathways. However, substantial quantities of undetected by-products were clearly produced in both cases, as evidenced by the low carbon balances observed (30\% and $70 \%$ for $1 \mathrm{Sn}-\mathrm{Beta}_{\mathrm{SSI}}$ and $1 \mathrm{Sn}-\mathrm{Beta}_{\mathrm{HDT}}$, respectively). Accordingly, the effluents of these reactions were also analysed by multiplicity edited ${ }^{1} \mathrm{H}^{-13} \mathrm{C}$ HSQC 2D NMR (Figure 10). 
Figure 10. (Left) Positive ( $\mathrm{CH}$ and $\mathrm{CH}_{3}$ groups) and negative $\left(\mathrm{CH}_{2}\right.$ groups) projections from edited $2 \mathrm{D}^{1} \mathrm{H}_{-}{ }^{13} \mathrm{C}$ HSQC NMR spectra recorded on the effluent of the operando UV-Vis glucose upgrading carried out by different preparations of Sn-Beta. (Right) Spectral region displaying signals from methyl-fructoside compounds.

Projections for the ${ }^{1} \mathrm{H}-{ }^{13} \mathrm{C}$ HSQC $2 \mathrm{D}$ spectra are shown in Figure 10, left, where positive signals derive from carbons carrying one or three hydrogen atoms, while negative intensities are derived for $\mathrm{CH}_{2}$ groups. Signal related to Me-Glu and Me-Fru are highlighted at 4.7-4.9 ppm and at $3.6 \mathrm{ppm}$, the latter of which are shown as surface plots in the ${ }^{1} \mathrm{H}-{ }^{13} \mathrm{C}$ HSQC $2 \mathrm{D}$ spectra of Figure 10, right. It is clear that whilst 1 Sn-Betass produces substantial quantities of Me-Glu and Me-Fru at these reaction conditions, $1 \mathrm{Sn}-\mathrm{Beta}_{\mathrm{HDT}}$ is less effective in producing alkyl-glycosides. In contrast, the NMR spectra reveal that $1 \mathrm{Sn}-\mathrm{Beta}_{\mathrm{HDT}}$ yielded much larger quantities of lactones $(2-2.5 \mathrm{ppm})$, and was much more effective at producing furanics and THM, as shown in Figure 10 (Left; signals at 5.9 ppm and 4.6 ppm). Among the non-selective absorbances $\left(\lambda_{360}, \lambda_{440}.\right), 1$ Sn-Beta ${ }_{\mathrm{HDT}}$ exhibited much higher intensity in the $\lambda_{360}$ region, whereas $1 \mathrm{Sn}-$ Beta $_{\mathrm{SSI}}$ exhibit much larger absorption at $\lambda_{440}$. Based on these findings, absorption at $\lambda_{360}$ can be attributed to by-products derived from 3DG, particularly $\beta$-dehydration products (THM, furanics) and lactones, whereas absorptions at $\lambda_{440}$ can be assigned to alkyl-glycoside products.

Although each correlation is empirical in nature, the balance of evidence achieved from these mechanistic studies allows us to correlate the optical intermediates and reaction pathways of this 
system in the following manner (Scheme 4): the $\lambda_{440}$ arises from the formation of alkyl glycosides, which is the dominant non-selective pathway at low temperature. In contrast, $\lambda_{360}$ relates to $\beta$ dehydration pathways, particularly the formation of THM and furanics, which are the major nonselective products at elevated temperature. In contrast, all selective pathways are characterised by absorbance at $\lambda_{330}$, which we believe is experimental confirmation that similar catalyst-substrate coordination occurs for all the selective glucose conversion processes (GI and RA).

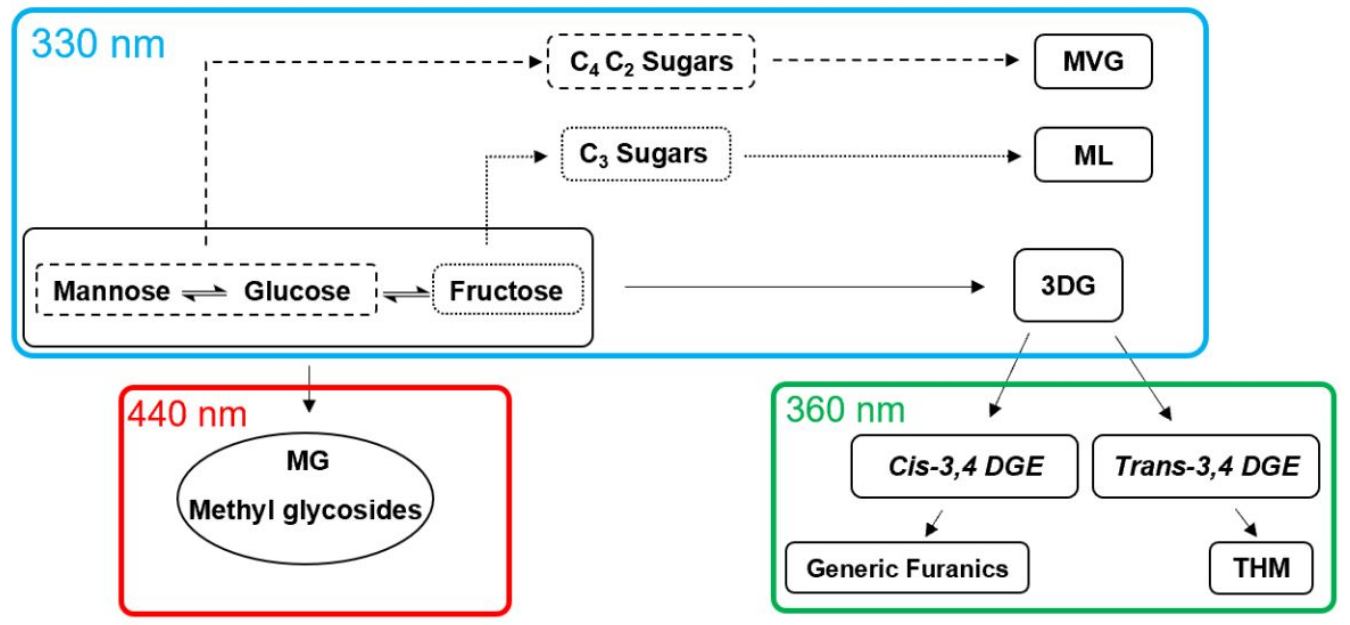

Scheme 4. Assignment of each UV-Vis absorption band to a particular glucose conversion pathway catalysed by Sn-Beta.

\section{Use of operando UV-Vis to probe deactivation phenomena}

Having assigned the various optical signals for intermediates that are generated during the continuous conversion of glucose over Sn-Beta (Scheme 4), the efficacy of the method to provide new information on various kinetic phenomena of the system was evaluated. In particular, the utility of operando UV-Vis spectroscopy to investigate the consequences of (partial) deactivation of the catalyst during continuous operation was explored.

Operando UV-Vis was therefore employed to monitor the continuous isomerisation of glucose to fructose over $10 \mathrm{Sn}-$ Beta $_{S S I}$ in methanol at $110{ }^{\circ} \mathrm{C}$ during a $50 \mathrm{~h}$ period of operation (Figure 11). The kinetic data generated during the operando reaction show that the system was characterized by an initially steep rate of deactivation over the first 5-10 h on stream, during which period conversion 
decreased from $55 \%$ to approximately $30 \%$. Over longer periods of operation, conversion continued to decrease albeit at a slower rate, eventually reaching a level of $15 \%$ after $50 \mathrm{~h}$ on stream. Although full selectivity towards fructose was not reached even at low rates of conversion, it is notable that the selectivity of the reaction was much lower at the initial stages of operation. Analysis of the time on stream data by the Levenspiel function revealed that deactivation occurred in three distinct stages over $10 \mathrm{Sn}-\mathrm{Beta}_{\mathrm{SSI}}$ at these operational conditions. ${ }^{38}$ These stages were characterised by deactivation rate constants of 0.17 (stage 1, 0-7 h), 0.03 (stage 2, 7-25 h) and 0.01 (stage 3, 25-50 h) X\%.h.'.
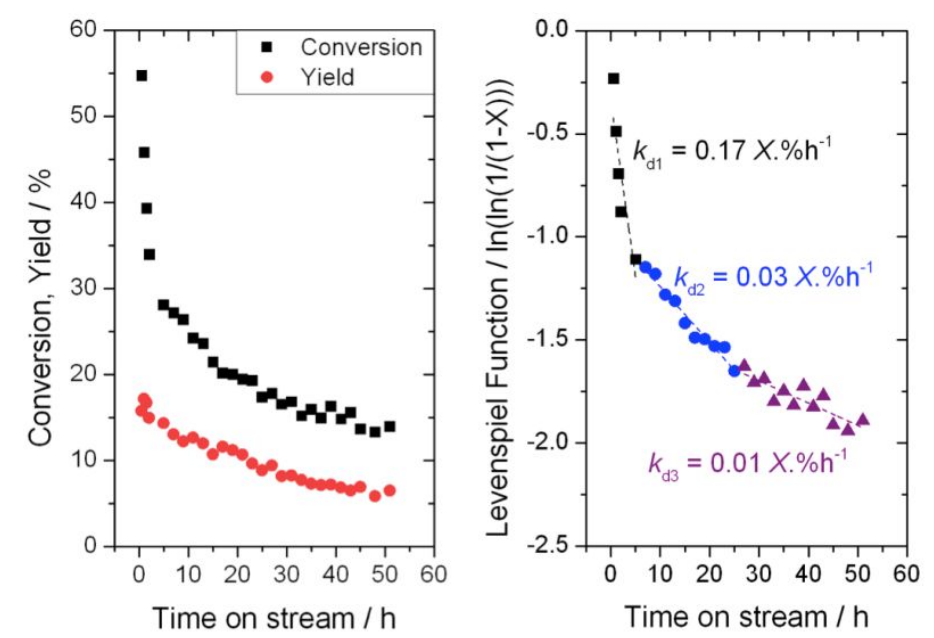

Figure 11. Kinetic data for glucose conversion over $10 \mathrm{Sn}-\mathrm{Beta}_{\mathrm{SSI}}$ at $110{ }^{\circ} \mathrm{C}$ in methanol. (Left) Glucose conversion and fructose yield of the catalyst as a function of time on stream. (Right) Levenspiel function demonstrating the deactivation constant of the reaction in different stages of operation. Reaction conditions: 1

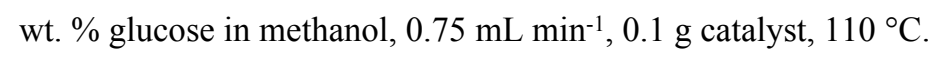
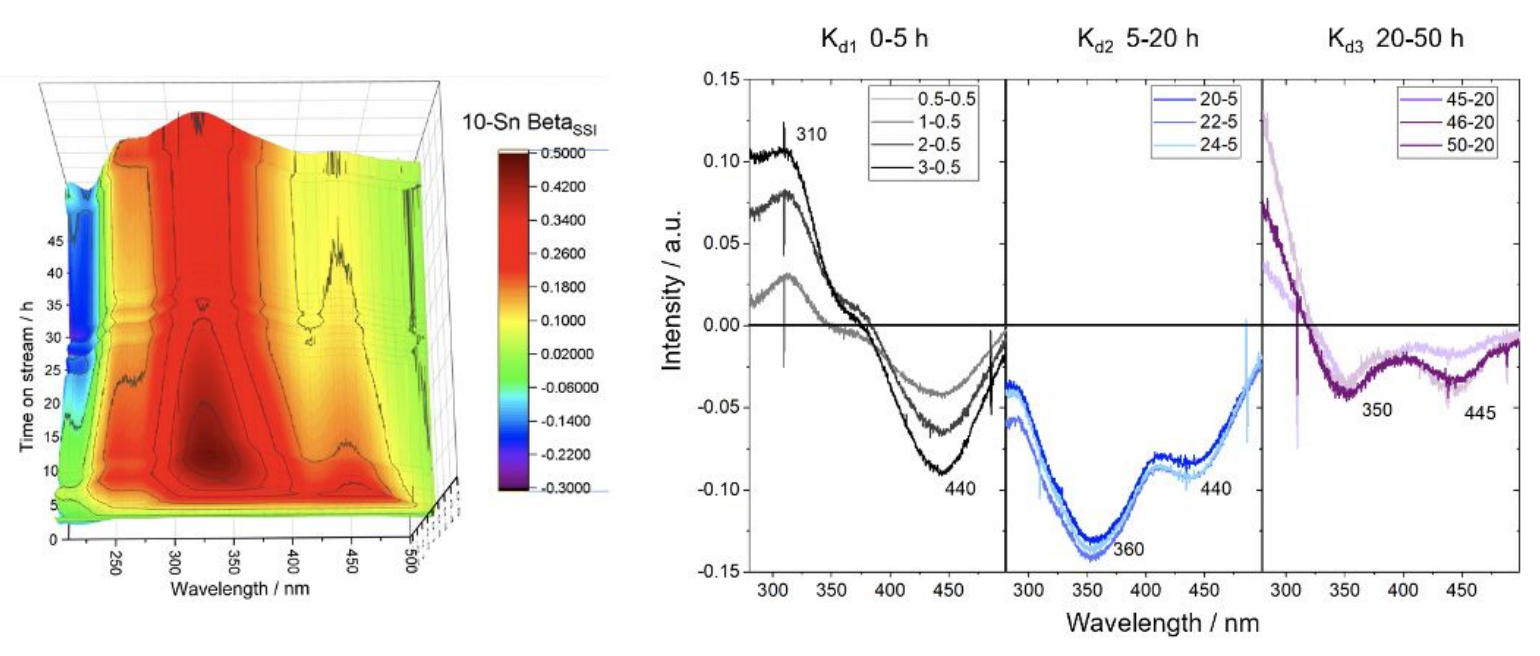
Figure 12. (Left) Operando UV-Vis spectrum for glucose upgrading over $10 \mathrm{Sn}-\mathrm{Beta}_{\mathrm{SSI}}$ at $110{ }^{\circ} \mathrm{C}$ in methanol. Reaction conditions: $1 \mathrm{wt}$ \% glucose in methanol, $0.75 \mathrm{~mL} \mathrm{~min}{ }^{-1}, 0.1 \mathrm{~g}$ catalyst, $110{ }^{\circ} \mathrm{C}$. (Right) Differential spectra for each stage of deactivation for $10 \mathrm{Sn}$-Beta $\mathrm{SSI}$. In the first stage of deactivation $\left(\mathrm{k}_{\mathrm{d} 1}\right)$, intense loss of signal of $\lambda_{440}$ is observed. In $\mathrm{k}_{\mathrm{d} 2}$, continued loss at $\lambda_{440}$ is observed alongside strong loss of $\lambda_{360}$. In $\mathrm{k}_{\mathrm{d} 3}$ a more homogenous loss of $\lambda_{340}$ and $\lambda_{440}$ is observed.

The operando UV-Vis spectra generated throughout the operational period are shown in Figure 12, left in differential mode, in which the spectrum recorded prior to introducing glucose into the feed (time $=0 \mathrm{~h}$ ), is subtracted from each spectrum. Warm colours (red) depict increased absorption relative to the fresh catalyst in methanol, whereas cold colours (blue) represent a decrease in absorption relative to the fresh catalyst in methanol.

Based on the assignments presented in Scheme 4, correlations of the operando UV-Vis spectra to the kinetic data were undertaken. Over the first hours on stream, conversion decreased rapidly $\left(k_{\mathrm{d} 1}=0.17\right.$ $X \% \mathrm{~h}^{-1}$ ) from a maximum of $55 \%$ at $0.5 \mathrm{~h}$ to $28 \%$ at $5 \mathrm{~h}$ on stream and the fructose yield also decreased, albeit more slowly, from $18 \%$ to $15 \%$. The most evident change in the operando UV-Vis spectra over this time period was the large decrease in intensity of the $\lambda_{440}$ feature (Figure 12, right, $k_{\mathrm{d} 1}$ ). Taken together, the rapid decrease in glucose conversion, coupled only to a minor decrease in yield but a major decrease in absorbance at $\lambda_{440}$ can be ascribed to rapid deactivation of the competitive alkylation pathway, in which glucose is converted to undesirable alkylated products, such as Me-Glu, which sequesters glucose into a non-reactive form. ${ }^{16}$

Over the following $20 \mathrm{~h}$ on stream (from $5 \mathrm{~h}$ to $25 \mathrm{~h}$ ), conversion continued to decrease, albeit at a slower rate $\left(k_{\mathrm{d} 2}=0.03 \mathrm{X} \% \mathrm{~h}^{-1}\right)$. During this period, the selectivity of the catalyst increased gradually, as a consequence of conversion decreasing at a faster rate than yield. This observation indicates that an additional non-selective pathway was primarily deactivating in this regime. Over this time frame, a clear narrowing of the absorbance in the $330-380 \mathrm{~nm}$ region was observed, due to a loss of intensity at $\lambda_{360}$ (Figure 12 , right, $k_{\mathrm{d} 2}$ ). Increased selectivity of the catalyst alongside the decrease in intensity at $\lambda_{360}$ suggests that deactivation of the $\beta$-dehydration pathways occurred during this period, resulting in decreased formation of furanics and $\beta$-dehydration products, such as THM. 
Over the remaining $25 \mathrm{~h}$ on stream (from $25-50 \mathrm{~h}$ ), limited changes were observed at $330 \mathrm{~nm}$, suggesting that the selective pathway occurring at this temperature (GI) remains relatively unperturbed over the final period of operation. This interpretation is supported by the relatively steady time on stream data obtained during this period, during which conversion and yield decreased minimally, and reaction selectivity was unaffected. However, at this stage, a (negative) high-energy signal at $220 \mathrm{~nm}$ clearly increased in magnitude. As we recently reported, this signal relates to deactivation of the catalyst due to interaction with the solvent, which is the primary mechanism of deactivation for the selective pathways of the process at these operational conditions. ${ }^{27}$ Hence, relatively slow deactivation of the selective pathway of the reaction occurs in this time frame. Taken together, operando UV-Vis analysis demonstrates that the deactivation of Sn-Beta during glucose conversion is nonhomogeneous, and is characterised by several events occurring at different periods of time, each of which impact the activity and selectivity of the system to different degrees.

In addition to providing mechanistic insight, the findings generated by operando UV-Vis suggest that the catalyst becomes more selective during operation as a consequence of more rapid deactivation of the non-selective reaction pathways associated with alkylation $\left(\lambda_{440}\right)$ and $\beta$-dehydration $\left(\lambda_{360}\right)$. To verify if this was the case, a final kinetic experiment was performed to evaluate the selectivity of the catalyst during different stages of continuous operation (Figure 13). In this experiment, glucose conversion was performed over $10 \mathrm{Sn}-\mathrm{Beta}_{\mathrm{SSI}}$ at $150^{\circ} \mathrm{C}$ firstly at a flow rate of $2 \mathrm{~mL} \mathrm{~min}{ }^{-1}$. Consistent with the experiment at $110{ }^{\circ} \mathrm{C}$ (Figure 11), rapid deactivation occurred over the first $20 \mathrm{~h}$ of operation, with conversion decreasing from $80 \%$ to $22 \%$. Over this time frame, relatively low quantities of selective products were observed in the effluent, with methyl lactate the major selective product produced at $<10 \%$ yield. After $20 \mathrm{~h}$, the flow rate of the feed was decreased from 2.0 to $0.5 \mathrm{~mL} \mathrm{~min}^{-1}$, thereby increasing the contact time of the reaction from $3 \mathrm{~s}$ to $12 \mathrm{~s}$, and allowing glucose conversion to be raised back to the initial level of conversion (approximately $90 \%$ ). In doing so, it was observed that even though the quantity of glucose converted was comparable to the early stages of operation, the process was substantially more selective after $20 \mathrm{~h}$ on stream than during the earlier stages of reaction, with methyl lactate produced at approximately $30 \%$ yield, versus $<10 \%$ during the early stages of operation. The change in selectivity supports the observations made by operando UV-Vis, 
and confirms that the catalyst becomes intrinsically more selective during continuous operation due to more rapid deactivation of the non-selective reaction pathways attributed to alkylation and $\beta$ dehydration.

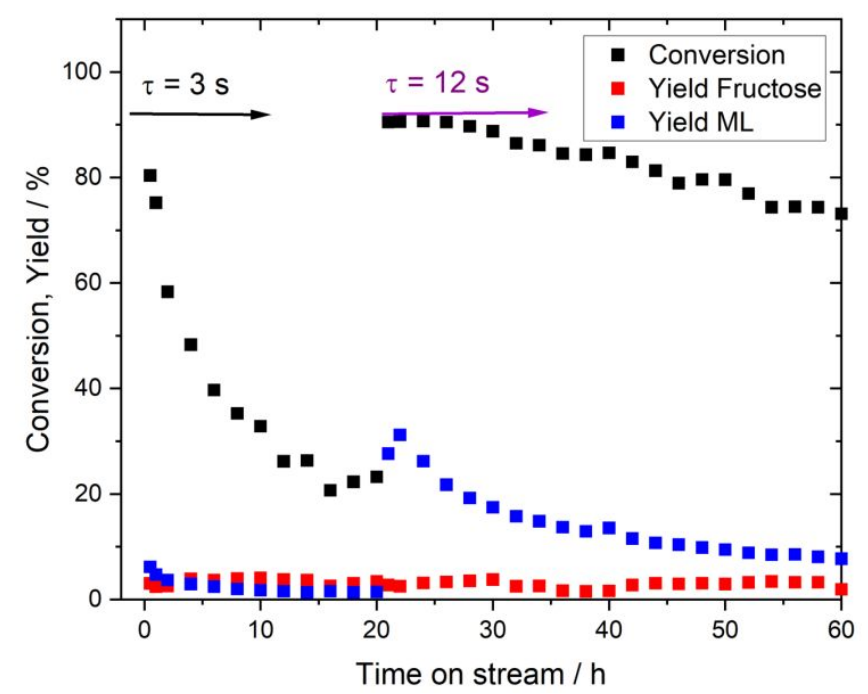

Figure 13. Kinetic data for glucose conversion over $10 \mathrm{Sn}-\mathrm{Beta}_{\mathrm{SSI}}$ at $150{ }^{\circ} \mathrm{C}$ in methanol at two different flow rate regimes. Reaction conditions: $1 \mathrm{wt}$. \% glucose in methanol, $0.1 \mathrm{~g}$ catalyst, $150{ }^{\circ} \mathrm{C}$. Flow rate of $2 \mathrm{~mL} \mathrm{~min}{ }^{-1}$ employed for first $20 \mathrm{~h}$, followed by $0.5 \mathrm{~mL} \mathrm{~min}^{-1}$ for the remaining $40 \mathrm{~h}$ reaction period.

\section{Conclusions}

This study follows the catalytic conversion of glucose over the Lewis acidic silicates, Sn-Beta and HfBeta, at operational conditions $\left(<150{ }^{\circ} \mathrm{C},<25\right.$ bar $)$ in a continuous flow reactor equipped with operando UV-Vis spectroscopy. Three transient absorption features related to the activation and conversion of glucose at various conditions were detected, at $330 \mathrm{~nm}, 360 \mathrm{~nm}$ and $440 \mathrm{~nm}$. Spectroscopic (high-field ${ }^{1} \mathrm{H}-{ }^{13} \mathrm{C}$ HSQC NMR) and kinetic cross-experiments allow each of these Snglucose interactions to be assigned to a particular class of selective $(330 \mathrm{~nm}$, glucose isomerisation and retro-aldol products) and non-selective $(360,440 \mathrm{~nm})$ products, which were found to arise from $\beta$ dehydration products $(360 \mathrm{~nm})$ and alkylation $(440 \mathrm{~nm})$ products, respectively. All selective pathways, including glucose isomerisation and retro-aldol processes, resulted in an absorbance at $330 \mathrm{~nm}$, suggesting that common catalyst-substrate interactions are present during all selective reaction processes. 
Based on the findings of operando UV-Vis, elements of the deactivation of stannosilicate catalysts during continuous operation were probed. These studies demonstrated that deactivation during glucose conversion is non-uniform, with different reaction pathways losing activity at different rates. In particular, the non-selective reaction pathway associated with alkylation $(440 \mathrm{~nm})$ deactivated fastest, followed by deactivation of the $\beta$-dehydration pathway $(360 \mathrm{~nm})$. Accordingly, the catalyst was found to increase in selectivity following partial deactivation, allowing its performance in later stages of the reaction cycle to be increased.

More broadly, the findings presented in this manuscript provide additional mechanistic insight into the glucose conversion process over Lewis acidic zeolites, and provide a new way to characterise such catalysts for biomass conversion without depending on probe molecules. In fact, although this study does not directly address the development of structure-activity relationships, it does reveal that very different catalyst-substrate interactions are observed as a function of catalyst preparation, choice of operative conditions and (partial) deactivation of the catalyst. We believe these optical features could therefore be exploited in future to unravel particular aspects of the structure-activity-lifetime relationships of Lewis acidic silicate catalysts during glucose upgrading, delivering a new tool to explore the properties of these materials and catalytic reactions.

\section{Experimental details}

\section{Catalyst synthesis}

A commercial zeolite Al- $\beta\left(\right.$ Zeolyst, $\mathrm{NH}_{4}{ }^{+}$-form, $\left.\mathrm{Si} / \mathrm{Al}=19\right)$ was dealuminated by treatment in $\mathrm{HNO}_{3}$ solution (13 $\mathrm{M} \mathrm{HNO}_{3}, 100{ }^{\circ} \mathrm{C}, 20 \mathrm{~mL} \mathrm{~g}^{-1}$ zeolite, 20 hours). Solid-state stannation was achieved by grinding the appropriate amount of tin (II) acetate with the necessary amount of dealuminated zeolite for 10 minutes in a pestle and mortar. Following this procedure, the sample was heated in a combustion furnace (Carbolite MTF12/38/400) to $550{ }^{\circ} \mathrm{C}\left(10{ }^{\circ} \mathrm{C} \min ^{-1}\right.$ ramp rate) first in a flow of $\mathrm{N}_{2}$ $(3 \mathrm{~h})$ and subsequently in a flow of air $(3 \mathrm{~h})$ for a total of $6 \mathrm{~h}$. Gas flow rates of $60 \mathrm{~mL} \mathrm{~min}{ }^{-1}$ were employed at all times. 
Hydrothermal synthesis of Sn-Beta was performed following a procedure described in reference 30 and 37: $30.6 \mathrm{~g}$ of TEOS was added to $33.1 \mathrm{~g}$ of TEAOH under careful stirring, forming a two-phase system. After 60-90 min, one phase was obtained and the desired amount of the tin source, typically $\mathrm{SnCl}_{4} \cdot 5 \mathrm{H}_{2} \mathrm{O}$, dissolved in $2.0 \mathrm{~mL}$ of $\mathrm{H}_{2} \mathrm{O}$ was added dropwise. The solution was then left for $48 \mathrm{~h}$ under stirring until a viscous gel was formed. The gel was finalised by the addition of $3.1 \mathrm{~g} \mathrm{HF}$ in $1.6 \mathrm{~g}$ of demineralized $\mathrm{H}_{2} \mathrm{O}$ yielding a solid gel with the molar composition $1.0 \mathrm{Si}: 0.005 \mathrm{Sn}: 0.02$ $\mathrm{Cl}^{-1}: 0.55 \mathrm{TEA}^{+}: 0.55 \mathrm{~F}^{-1}: 7.5 \mathrm{H}_{2} \mathrm{O}$. The obtained gel was transferred to a Teflon lined stainless steel autoclave and kept for 7 days at $140{ }^{\circ} \mathrm{C}$ to crystallise. The obtained crystals were filtered and washed with deionised water. Calcination at $550{ }^{\circ} \mathrm{C}\left(2{ }^{\circ} \mathrm{C} \mathrm{min}^{-1}\right)$ for $6 \mathrm{~h}$ under static air was carried out in order to remove the organic template.

\section{Kinetic studies}

Continuous glucose conversion was performed in a plug flow, stainless steel, tubular reactor. The catalyst was pelletised (size fraction 63 and $77 \mu \mathrm{m}$ ) and densely packed into a 1/4" stainless steel tube (4.1 mm internal diameter). Two plugs of quartz wool and a frit of $0.5 \mu \mathrm{m}$ held the catalyst in location. Temperature control was achieved by a thermostatted oil bath held at the desired reaction temperature, and pressurization was achieved by means of a backpressure regulator. Aliquots of the reaction solutions were taken periodically from a sampling valve placed after the reactor and analysed by an Agilent 1260 Infinity HPLC equipped with a Hi-Plex Ca column and ELS detector, and quantified against an external standard (sorbitol) added to the sample prior to the injection.

\section{NMR spectroscopy}

Multiplicity-edited ${ }^{1} \mathrm{H}-{ }^{13} \mathrm{C}$ HSQC spectra were acquired by using a standard pulse sequence (hsqcedetgpsisp.2) on an $800 \mathrm{MHz}$ Bruker Avance III NMR spectrometer equipped with a TCI zgradient CryoProbe and a SampleJet sample changer. The spectra were obtained at $298 \mathrm{~K}$ by sampling 1024 and 128 complex data points in the free induction decay for acquisition times of 106 and 4.5 milliseconds in the direct $\left({ }^{1} \mathrm{H}\right)$ and indirect $\left({ }^{13} \mathrm{C}\right)$ dimensions, respectively. The indirect dimension was sampled in a traditional manner rather than by non-uniform sampling and 8 transients were averaged with an inter-scan relaxation delay of 1.2 seconds, resulting in an experiment time of $\sim 46$ minutes per 
${ }^{1} \mathrm{H}-{ }^{13} \mathrm{C}$ HSQC experiment. All spectra were processed with a shifted sine-bell apodization function and extensive zero filling in both dimensions in Topspin 4.0.6 and analysed in the same software. Figure 10 displays positive projections of all rows in the respective two-dimensional spectra as derived with Topspin 4.0.6.

\section{Catalyst Characterisation}

Operando UV-Vis measurements were performed with a home-made tubular reactor constructed from an optically transparent material equipped with fibre optic UV-Vis probe. UV-Vis measurements were performed with a light source (Ocean Optics DH-2000), spectrometer (Maya 2000 Pro, Ocean Optics) and a $600 \mu \mathrm{m}$ UV-Vis fibre. The light was directed onto the optically transparent reactor column, located within a heated aluminium block. A thorough explanation of the system can be found in the Supporting Information (Figures S1-S3)

\section{Author contributions \\ The manuscript was written through contributions of all authors, and all authors have given approval to the final version of the manuscript.}

\section{Supporting Information}

Supporting spectroscopic data are supplied in the Supporting Information.

\section{Acknowledgements}

$\mathrm{CH}$ gratefully appreciates the support of The Royal Society, for provision of a University Research Fellowship (UF140207, URF\R\201003) and enhanced research grant funding (RGF/EA/180314). CH and LB are grateful to Haldor Topsøe A/S for PhD studentship funding. $800 \mathrm{MHz}$ NMR spectra were recorded on the spectrometer of the DTU NMR Center supported by the Villum Foundation.

\section{References}


(1) Vennestrøm, P. N. R.; Osmundsen, C. M.; Christensen, C. H.; Taarning, E. Beyond Petrochemicals: The Renewable Chemicals Industry. Angew. Chem. Int. Ed. 2011, 50, 10502-10509.

(2) Tuck, C. O.; Perez, E.; Horvath, I. T.; Sheldon, R. A.; Poliakoff, M. Valorization of Biomass: Deriving More Value from Waste. Science. 2012, 338, 695-699.

(3) Zheng, J.; Suh, S. Strategies to Reduce the Global Carbon Footprint of Plastics. Nat. Clim. Chang. 2019, 9, 374-378.

(4) Delidovich, I.; Leonhard, K.; Palkovits, R. Cellulose and Hemicellulose Valorisation: An Integrated Challenge of Catalysis and Reaction Engineering. Energy Environ. Sci. 2014, 7 (9), 28032830.

(5) Climent, M. J.; Corma, A.; Iborra, S. Conversion of Biomass Platform Molecules into Fuel Additives and Liquid Hydrocarbon Fuels. Green Chem. 2014, 16, 516-547.

(6) Delidovich, I.; Palkovits, R. Catalytic Isomerization of Biomass-Derived Aldoses: A Review. ChemSusChem 2016, 9, 547-561.

(7) Zhang, X.; Wilson, K.; Lee, A. F. Heterogeneously Catalyzed Hydrothermal Processing of C5-C6 Sugars. Chem. Rev. 2016, 116, 12328-12368.

(8) Moliner, M.; Roman-Leshkov, Y.; Davis, M. E. Tin-Containing Zeolites Are Highly Active Catalysts for the Isomerization of Glucose in Water. Proc. Natl. Acad. Sci. 2010, 107, 6164-6168.

(9) Holm, M. S.; Saravanamurugan, S.; Taarning, E. Conversion of Sugars to Lactic Acid Derivatives Using Heterogeneous Zeotype Catalysts. Science. 2010, 328, 602-605.

(10) Dijkmans, J.; Gabriëls, D.; Dusselier, M.; de Clippel, F.; Vanelderen, P.; Houthoofd, K.; Malfliet, A.; Pontikes, Y.; Sels, B. F. Productive Sugar Isomerization with Highly Active Sn in Dealuminated $\beta$ Zeolites. Green Chem. 2013, 15, 2777-2785.

(11) Moliner-Marin, M.; Roman-Leshkov, Y.; Davis, M. E.; Nikolla, E. Isomerisation of glucose to fructose by means of Lewis acid-zeolite catalysts. EP3067362A1, 2011, 2, 1-23.

(12) Dusselier, M.; VanWouwe, P.; deClippel, F.; Dijkmans, J.; Gammon, D. W.; Sels, B. F. Mechanistic Insight into the Conversion of Tetrose Sugars to Novel $\alpha$-Hydroxy Acid Platform Molecules. ChemCatChem 2013, 5, 569-575. 
(13) Tolborg, S.; Meier, S.; Sádaba, I.; Elliot, S. G.; Kristensen, S. K.; Saravanamurugan, S.; Riisager, A.; Fristrup, P.; Skrydstrup, T.; Taarning, E. Tin-Containing Silicates: Identification of a Glycolytic Pathway via 3-Deoxyglucosone. Green Chem. 2016, 18, 3360-3369.

(14) Tolborg, S.; Sádaba, I.; Osmundsen, C. M.; Fristrup, P.; Holm, M. S.; Taarning, E. TinContaining Silicates: Alkali Salts Improve Methyl Lactate Yield from Sugars. ChemSusChem 2015, 8, 613-617.

(15) Padovan,D.; Tolborg,S.; Botti,L.; Taarning,E.; Sad́aba,I.; Hammond, C. Overcoming Catalyst Deactivation during the Continuous Conversion of Sugars to Chemicals: Maximising the Performance of Sn-Beta with a Little Drop of Water. React. Chem. Eng. 2018, 3, 155-163.

(16) Tosi, I.; Riisager, A.; Taarning, E.; Jensen, P. R.; Meier, S. Kinetic Analysis of Hexose Conversion to Methyl Lactate by Sn-Beta: Effects of Substrate Masking and of Water. Catal. Sci. Technol. 2018, 8, 2137-2145.

(17) Botti, L.; Navar, R.; Tolborg, S.; Martinez-Espin, J. S.; Padovan, D.; Taarning, E.; Hammond, C. Influence of Composition and Preparation Method on the Continuous Performance of Sn-Beta for Glucose-Fructose Isomerisation. Top. Catal. 2019, 62, 1178-1191.

(18) Wolf, P.; Liao, W. C.; Ong, T. C.; Valla, M.; Harris, J. W.; Gounder, R.; van der Graaff, W. N. P.; Pidko, E. A.; Hensen, E. J. M.; Ferrini, P.; et al. Identifying Sn Site Heterogeneities Prevalent Among Sn-Beta Zeolites. Helv. Chim. Acta 2016, 99, 916-927.

(19) Hammond, C.; Padovan, D.; Al-Nayili, A.; Wells, P. P.; Gibson, E. K.; Dimitratos, N. Identification of Active and Spectator Sn Sites in Sn- $\beta$ Following Solid-State Stannation, and Consequences for Lewis Acid Catalysis. ChemCatChem. 2015, 7, 3322-3331.

(20) Yakimov, A. V.; Kolyagin, Y. G.; Tolborg, S.; Vennestrøm, P. N. R.; Ivanova, I. I. ${ }^{119}$ Sn MAS NMR Study of the Interaction of Probe Molecules with Sn-BEA: The Origin of Penta- and Hexacoordinated Tin Formation. J. Phys. Chem. C 2016, 120, 28083-28092.

(21) Gunther, W. R.; Michaelis, V. K.; Griffin, R. G.; Roman-Leshkov, Y. Interrogating the Lewis Acidity of Metal Sites in Beta Zeolites with 15N Pyridine Adsorption Coupled with MAS NMR Spectroscopy. J. Phys. Chem. C 2016, 120, 28533-28544. 
(22) Boronat, M.; Concepción, P.; Corma, A.; Renz, M.; Valencia, S. Determination of the Catalytically Active Oxidation Lewis Acid Sites in Sn-Beta Zeolites, and Their Optimisation by the Combination of Theoretical and Experimental Studies. J. Catal. 2005, 234, 111-118.

(23) Harris, J. W.; Cordon, M. J.; Di Iorio, J. R.; Vega-Vila, J. C.; Ribeiro, F. H.; Gounder, R. Titration and Quantification of Open and Closed Lewis Acid Sites in Sn-Beta Zeolites That Catalyze Glucose Isomerization. J. Catal. 2016, 335, 141-154.

(24) Yakimov, A. V.; Kolyagin, Y. G.; Tolborg, S.; Vennestrøm, P. N. R.; Ivanova, I. I. ${ }^{119}$ Sn MAS NMR Study of the Interaction of Probe Molecules with Sn-BEA: The Origin of Penta- and Hexacoordinated Tin Formation. J. Phys. Chem. C 2016, 120, 28083-28092.

(25) Vimont, A.; Thibault-Starzyk, F.; Daturi, M. Analysing and understanding the active site by IR spectroscopy. Chem. Soc. Rev. 2010, 39, 4928-4950.

(26) Meier, S. In-Situ Annotation of Carbohydrate Diversity, Abundance, and Degradability in Highly Complex Mixtures Using NMR Spectroscopy. Anal. Bioanal. Chem. 2014, 406, 7763-7772.

(27) Padovan, D.; Botti, L.; Hammond, C. Active Site Hydration Governs the Stability of Sn-Beta during Continuous Glucose Conversion. ACS Catal. 2018, 8, 7131-7140.

(28) Elliot, S. G.; Tolborg, S.; Sádaba, I.; Taarning, E.; Meier, S. Quantitative NMR Approach to Optimize the Formation of Chemical Building Blocks from Abundant Carbohydrates. ChemSusChem 2017, 10, 2990-2996.

(29) Hammond, C.; Conrad, S.; Hermans, I. Simple and Scalable Preparation of Highly Active Lewis Acidic Sn- $\beta$. Angew. Chem. Int. Ed. 2012, 51, 11736-11739.

(30) Botti, L.; Kondrat, S. A.; Navar, R.; Padovan, D.; Martinez-Espin, J. S.; Meier, S.; Hammond, C. Solvent-Activated Hafnium-Containing Zeolites Enable Selective and Continuous GlucoseFructose Isomerisation. Angew. Chemie - Int. Ed. 2020, 59, 20017-20023.

(31) Assary, R. S.; Curtiss, L. A. Comparison of Sugar Molecule Decomposition through Glucose and Fructose: A High-Level Quantum Chemical Study. Energy and Fuels 2012, 26, 1344-1352.

(32) Taarning, E.; Saravanamurugan, S.; Holm, M. S.; Xiong, J.; West, R. M.; Christensen, C. H. Zeolite-Catalyzed Isomerization of Triose Sugars. ChemSusChem 2009, 2, 625-627. 
(33) Dusselier, M.; De Clercq, R.; Cornelis, R.; Sels, B. F. Tin Triflate-Catalyzed Conversion of Cellulose to Valuable ( $\alpha$-Hydroxy-) Esters. Catal. Today 2017, 279, 339-344.

(34) Chang, C. C.; Wang, Z.; Dornath, P.; Je Cho, H.; Fan, W. Rapid Synthesis of Sn-Beta for the Isomerization of Cellulosic Sugars. RSC Adv. 2012, 2, 10475-10477.

(35) Yang, G.; Pidko, E. A.; Hensen, E. J. M. The Mechanism of Glucose Isomerization to Fructose over Sn-BEA Zeolite: A Periodic Density Functional Theory Study. ChemSusChem 2013, 6, $1688-1696$.

(36) Elliot, S. G.; Taarning, E.; Madsen, R.; Meier, S. NMR Spectroscopic Isotope Tracking Reveals Cascade Steps in Carbohydrate Conversion by Tin-Beta. ChemCatChem 2018, 10, 1414 1419.

(37) Tolborg, S.; Katerinopoulou, A.; Falcone, D. D.; Sadaba, I.; Osmundsen, C. M.; Davis, R. J.; Taarning, E.; Fristrup, P.; Holm, M. S. Incorporation of Tin Affects Crystallization, Morphology, and Crystal Composition of Sn-Beta. J. Mater. Chem. A 2014, 2, 20252-20262

(38) Levenspiel, O. Industrial \& Engineering Chemistry Research; 1999; 38, 4140-4183.

\section{Table of contents graphic}

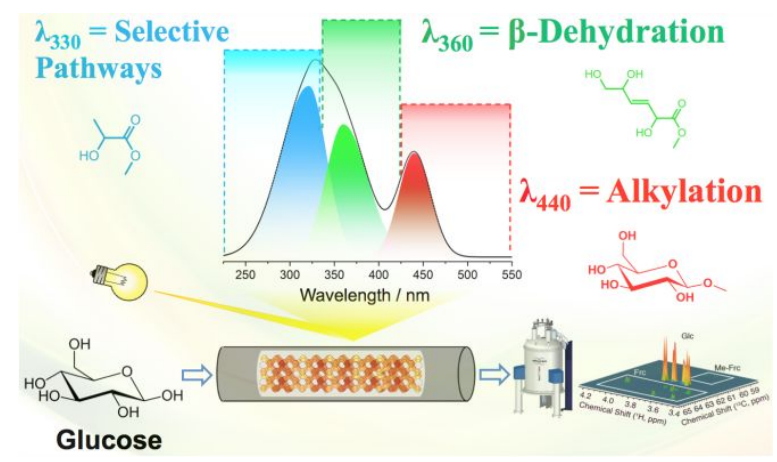

